\title{
ARCHIVO
}

\section{Danza de Santa Genoveva}

Presentamos un nuevo texto de aquellas representaciones que se hacían en los pueblos de la comarca leonesa de la Cabrera, con motivo de la festividad del Corpus o de las fiestas patronales, y que iban acompañadas de la Danza de paloteo ${ }^{1}$. Este manuscrito, probablemente de comienzos de siglo, lo conservan en el pueblo cabreirés de Nogar. En la representación intervienen ocho personajes, cuatro moros y cuatro cristianos, más la Dama (en este caso, Genoveva de Bravante).

El tema de Genoveva de Bravante, esposa inocente y calumniada, tuvo una gran difusión, tanto en romances y narraciones cortas de tradición oral, como en novelas y dramas. Quizá uno de los relatos novelados más conocidos sea el del jesuita francés del siglo XVII, P. de Cerisiers, titulado L'Innocence reconue (París, 1647), revisado más tarde por el abad Richard $^{2}$. En España se halla recogida la vida de Genoveva en romances y cuentos de tradición oral, así como en otro tipo de narraciones ${ }^{3}$.

1 Son ya cinco los manuscritos de estas representaciones que hemos encontrado en pueblos de la Cabrera. En esta misma revista apareció el texto de sLa Danza de Carlomagno. (RDTP, XIVI, 1991, pp. 311-350). También publicamos en la Revista de Folklore el texto de "La Danza de San Antonio (núm. 133, 1992, pp. 12-22) y de .La guerra de Melilla. (núm. 159, 1994, pp. 75-79). Está en prensa, en la revista Tierras de León, .La Danza del rey Nabucodonosor.

2 Cf. Charles NISARD, Histoire des Livres Populaires ou de la Littérature $d u$ Colportage... (Paris, 1864) (2. ${ }^{a}$ ed.), pp. 423-425.

3 Mi buen amigo Julio Camarena me informa de que este tema se encuentra en cuentos extremeños, murcianos, manchegos y andaluces; también en Hispanoamérica y en Portugal. Para los romances puede consultarse el Romancero General de Durán (B.A.E., vol. XVI, núms. 1309-1310) y F. AGUILAR PIÑAL, Romances populares del siglo XVIII (Madrid: C.S.I.C., 1972), núms. 1807-1811. Y Julio CARO BAROJA cita la Nueva historia de la virtuosa y mártir Genoveva, en la :Biblioteca Moderna", tres pliegos, 24 páginas, seis capítulos, cf. Ensayo sobre la Literatura de cordel (Madrid: Revista de Occidente, 1969), p. 343 , nota 8 . 


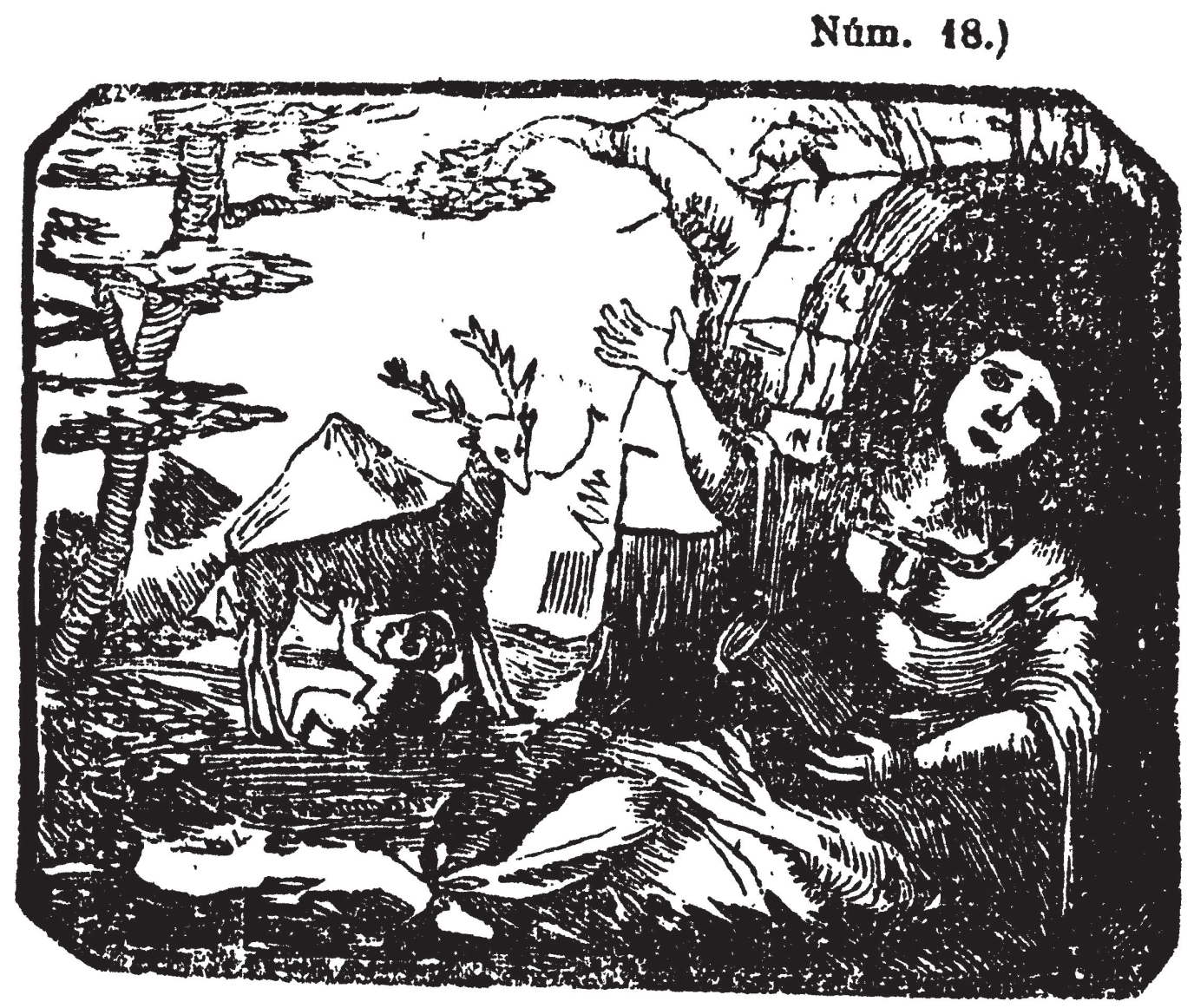

\section{RELACION HISTÓRICA}

en quo veliere la peregrina y trajgica vida le la pentento

anacoreta, la princessa de Brabante.

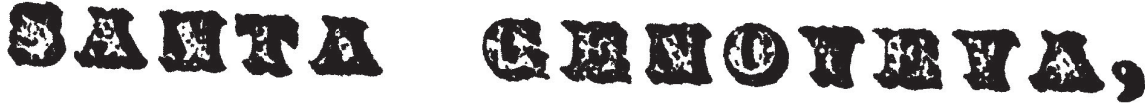

MCADA DE LA venfoica Historia de LA Misma saxta.

No canto fingidos bechos. ni invento falsas novelas que en doradas copas brindan estragos á la inocencia. Canto solo para dar un disceno donde vea el mundo todo, que Dios. amoroso Padre, vela. faroreciendo al que fin: de sus preceptos la setion

Pliego de cordel, Madrid, Despacho: Sucesores de Hernando, Arenal 11. Relación Histórica en que se refiere la peregrina y trágica vida de la penitente anacoreta, la princesa de Brabante... Biblioteca del Instituto de Filología del C.S.I.C. (R. 60.291). 
TEXTO DEL MANUSCRITO

Da principio el Rey moro

Valientes soldados míos que os llamais sarracenos, caballeros esforzados de tan conocido esfuerzo, ya sabeis que mi valor consigue, con gran esfuerzo, posesión de las Provincias que en Occidente gobierno. Por lo cual me determino, por no pagar este fuero, de hacerme Señor de Europa y de entrar por ella adentro conquistando a los cristianos, hasta dejarlos exentos de toda su posesión, sacándolos de su centro. $\mathrm{Y}$ así pretendo juntar un tan numeroso ejército, que nunca en el Occidente tan asombroso lo vieron. En los Campos de Turena podemos hacer asiento, extendiéndose la gente desde allí a los Pirineos, en donde hemos de esperar al grande Carlos tercero con doce mil de a caballo $\mathrm{y}$ de a pie número recio, con los caballeros nobles, tan fuertes como guerreros. $\mathrm{Y}$ así tengo ordenado y espero vuestro consejo no tardes en declararlo lo que sentís en aquesto.

\section{Segundo moro}

Invicto Rey y Señor, que gozais de tanta honra, de vuestro valor y esfuerzo hoy todo el mundo se asombra, por lo cual todos estamos bien dispuestos por ahora para entrar por toda la Francia, conquistando toda Europa, y así dispone al momento que marche la gente toda.

\section{Tercer moro}

Vuestra determinación, Señor, por buena aprobamos, porque es cierto que la Francia tiene golosos bocados, y así, Señor, puede [sic] ir en nosotros confiado, que te seguiremos todos sin perder punto ni paso.

\section{Cuarto moro}

Con un delicioso ruido de clarines y de cajas, vaya marchando la tropa, sin detenernos en nada, conquistando toda Europa hasta dejarla asolada.

Rey moro

Ea, pues, como leones, soldados de gran valor, 
sarracenos esforzados, pelear todos con valor; la batalla está dispuesta, ninguno tenga temor. Estese la Armada quieta mientras tomamos razón, si está dispuesta la Francia para tan grande función. Alerta, los centinelas, y los guardias al tenor, todas las cosas dispuestas sin la menor dilación.

\section{(Córrese la Danza)}

\section{Conde, que es primero derecho}

Amada y querida prenda, esposa, dueña y señora, Genoveva de mi vida, dulce y hermosa paloma, procura ahora dejar, que es preciso, amada esposa, el sentimiento y los llantos, que mi corazón acongojan. Dejad ya demostraciones que a nuestras almas asombran. Mucho lo siento el dejaros en mi Palacio tan sola, más bien sabeis que no puedo, menos de perder gran honra, quedarme con vos aquí, sin haber causa notoria. Porque si los grandes faltan, tomarán la tierra toda los moros y sarracenos, señoreando a toda Europa. El caudillo de los moros, alerta tiene sus tropas en los Campos de Turena ya los sarracenos toman.
Encargada os dejo a Golo, en quien confío mi honra, que espero que cuidará de vos, como mi señora.

$\mathrm{Y}$, así, querida del alma, con Dios te quedas, señora, volveré cuan presto pueda a verte, querida esposa, que es precisa esta partida y si no pierdo mi honra.

\section{Dama}

¡Oh! pobre de mí, inocente, cual ha sido mi fortuna. De pocos meses casada, me quereis dejar viuda. Como viviré sin vos y sin compañía ninguna. Quién podrá darme consuelo a esta tan grande angustia. Adiós, esposo querido, mi alma vaya con la tuya.

Conde, que es primero derecho

A vos, Reina de los cielos, Madre de mi Redentor, a vos encomiendo mi esposa, mirad vos por mi honor. Pues sois Madre de piedad, os suplico con fervor que la libreis de peligros $y$ le deis vuestro favor. Adiós, esposa querida, la Virgen queda con vos.

(Abora marcha el Conde a donde está el cuarto, que es Golo, y Golo se va a donde está la Dama y dice el Conde, primero derecho) 


\section{Conde}

Caballeros esforzados, fuertes como leones, sabed que los sarracenos han expedido una orden de entrarse por toda Francia, según ellos los disponen. Por lo cual, vasallos mios, sin perder punto ni orden estareis todos dispuestos con leales corazones para salir al encuentro antes que la tierra tomen. Nadie quiera que los moros de nuestras tierras gocen los frutos de nuestras tierras haciendo desolaciones. $\mathrm{Y}$, así, estareis prevenidos, pues es ésta nuestra orden.

Segundo derecho

Nuestra obligación, Señor, es de seguir tus pisadas y así no dudes que todos te seguiremos con armas matando los sarracenos, como si fueran marranos, quitando todas las vidas aunque hubiera más que paja.

\section{Tercero derecho}

Es muy cierto, gran Señor, $y$ en eso no hay que dudarlo, que a los primeros encuentros les quitaremos las caras, les cortaremos los brazos y arrancaremos las armas, dejándolos todos muertos $y$ en un instante, sin falta.

$Y$, así, dispone la gente, porque el moro se adelanta.

\section{Primero derecho, Conde}

Ea, pues, amigos míos, la orden está ya dada, vaya marchando la tropa, tóquense luego las cajas, y a los campos de Turena se enderecen sin tardanza, por los altos Pirineos vaya pasando la Armada. Y, también, capitán mío, parte con vigilancia

y a mi esposa en propia mano le entregarás esta carta.

Le dirás en donde quedo y con saluz [sic], a Dios gracias, que no tenga pena alguna, que espero en la Virgen Santa de ponerme en su presencia antes de un año, sin falta. Marcha luego de contado, no te detengas en nada.

Segundo derecbo

A cumplir lo que mandas me parto, con gran cuidado. Antes que marche la tropa volveré con el recado.

(Segundo derecho va con la embajada basta Golo y dice segundo derecho al cuarto que es Golo)

Segundo derecho

El cielo os quiera guardar, 
señor de aqueste Palacio, cartas para la princesa, dadme licencia, que traigo de la ciudad de Avinion [sic], donde está su esposo amado.

Golo dice

Bien venido seais vos, embajador afamado, si traeis alguna nueba [sic], no tardeis en declararlo, y luego podreis entrar a decirle ese recado, pues la Condesa está sola, retirada allá en su cuarto.

\section{Segundo derecho}

Dios os pague la fineza, vivas muy felices años.

\section{(Llégase a los pies de la Dama y} dicele)

Bien hallada seais, señora, Princesa tan alabada, de parte de vuestro esposo os traigo aquesta carta y dice que espera en Dios y la Virgen soberana de venir antes de un año, que no tengas pena tanta.

(Dama, lee la carta $y$ dice)

El cielo quiera premiarte tanto valor y agasajo, que cartas tan de mi gusto hoy, a mi, me has entregado. Marcha luego y le dirás que venga con grande celo, que venga cuan presto pueda, porque mucho lo deseo.

Esta carta le darás, conforme yo te la entrego.

\section{Segundo derecho}

Ese recado, Señora, haré con grande contento. Dios quede en tu compañía y a mi me dé gran acierto.

(Vuelve bailando la embajada y dice el embajador)

Caminando largos días, y con muy largas jornadas, vengo ya de vuestras tierras y os traigo aquestas cartas de parte de vuestra esposa, que queda buena y bizarra. Abrirlas y lo vereis, con lo demás que os manda.

Conde (lee la carta)

Amado y querido esposo, dueño y señor de mi alma, de tu salud la noticia me causó alegría tanta que nadie, sino tú solo, puede llegar a extremarla. Yo quedo buena, y con fruto de tus muy buenas entrañas, esperando tu venida que, ojalá, fuera mañana. Dios quiera darte fortuna y guardar también tu alma. Con eso, guardaos, adiós, esposo mío del alma. 
(Ciérrala, y dice primero derecho, que es el Conde)

Por cierto me da a entender que ha quedado preñada, de lo que me alegro mucho, Dios la quiera dar bonanza. $Y$ vos descansad ahora, porque mañana, sin falta, ya que los moros esperan, hemos de dar la batalla.

(Danzan y luego dice Golo)

Golo

Muy dulce y señora mía, princesa noble y honrada, ya sabeis la grande pena que por vos pena mi alma. No encuentro en vos un alivio, antes, siempre estais ingrata. Yo pienso perder la vida, pues mi alma, enamorada, de vos padece rigores, sin compasión ni mudanza. Vuestro rigor no permite, ni permitió a mi constancia, otorgar lo que merece mi amor y desdicha tanta. De dolor me desespero, si me falta la esperanza, mirad que me respondeis, prenda querida del alma.

\section{Dama}

Verdaderamente, Golo, que vuestro atrevido intento me ha sacado de juicio, siendo tan malo y protervo.
Y si de él no desistis, por mi nobleza prometo de tomar de vos venganza, de tan privado yerro.

Tratad luego de enmendaros

y pedid perdón al cielo, y no os acordeis más de eso $\tan$ atrevido y grosero.

\section{Golo}

Viva Dios, que de esta vez he de vengarme, si puedo, viendo mi amor despreciado, más quisiera verme muerto. He de discurrir un modo para vengarme al momento. Leales amigos míos, en quienes he confiado, y de todos mis designios siempre consejo he tomado, el dolor grande que tengo pienso ahora declararlo; que es el todo en que consiste la honra de nuestro amo. La princesa está preñada de un indigno criado, a mi me quedó encargada, es preciso esto ocultarlo. Por lo cual me determino ponerla con gran cuidado en un sitio, recogida, en la torre del Palacio, hasta que de todo esto de aviso a nuestro amo, que en esto va nuestra honra. $\mathrm{Y}$, así, marcha de contado y coged a la princesa, sin poner ningún reparo. En la torre la prendeis, en el calabozo alto, 
y todo esto en secreto, porque no llegue a ser claro.

Esto es lo que conviene y, así, id a ejecutarlo.

\section{Tercero derecho}

Grande admiración me causa lo que vos habeis contado, porque nuestra ama es muy santa, no que tan mal haya obrado. $\mathrm{Si}$ es preciso obedeceros, caiga sobre vos el cargo, y así voy luego a prenderla, sin perder tiempo ni paso.

\section{Golo}

Id luego, sin detención, porque estoy bien informado.

(Coge la dama el tercero derecho $y$ préndela y luego dice)

Tercero derecho

Venid conmigo, señora, a la torre del palacio, donde han mandado prenderos, sin que pueda remediarlo.

\section{Dama}

¿Qué es aquesto, cielo santo, que traición esta tan grande? ¿Cómo, mi Dios, permitis que yo tantos males pase, conociendo mi ignorancia y que, en mí, no hay culpa grave? ¡Oh! pérfido y desleal Golo, cómo tan cruel te haces, que yo por guardar mi honra padezco aquí tantos males. ¡Oh, esposo de mi vida!, quién pudiera declararte de este traidor mayordomo el atrevimiento grande. Por guardar fidelidad me veo aquí, en un instante, metida en aquesta torre, como si fuera yo infame. Preñada ya de ocho meses, sin poder yo ver a nadie. ¿Donde estás, mi dulce esposo? ¡Oh! quién pudiera avisarte que el fruto de tus entrañas prisionero está en dos partes. ¡Oh! padre muy querido, ¿dónde estás que esto no sabes? A vos, Virgen soberana, os pido en aqueste lance me presteis vuestro favor, porque el dolor no me acabe.

\section{Tercero derecho}

Quedad vos con Dios, señora, $\mathrm{El}$ os alivie y ampare

(Vuelve a Golo, tercero derecbo, y dice:)

Ya he cumplido, señor, todo lo que vos mandastes, más la condesa, nuestra ama, de vos muchas quejas da: que es muy falso lo que dices y que promete venganza. Mirad muy bien lo que haceis, no sea el diablo que os engañe. 
Golo

Déjala, que está bien presa porque bien lo ha merecido, no la creais sus embustes, creedme lo que yo digo, hasta que venga nuestro amo, que le daremos aviso.

(Danzan y dice el Rey moro)

Rey moro

Valerosos sarracenos, ya sabeis que los cristianos tienen ya la gente junta y vienen ya ordenados.

Ya Vinion [sic] está tomada, según yo me persuado, no se detenga la gente, vayan luego caminando.

\section{Segundo moro}

Vámonos sin detenernos, hagamos una derrota, entrando por toda Francia, matando la gente toda.

\section{Tercer moro}

Los cristianos vienen cerca, tomemos luego las armas, ya suenan todas las tropas, los clarines y las cajas. Por la falda de los montes se enderece la vanguardia, registrando todo bien, no quede alguna emboscada, puede hacernos grave daño, sin poder tomar venganza.
Cuarto moro

Mi amo, Rey sarraceno, vaya marchando la tropa, yo llevaré la bandera, sígame la gente toda.

Rey moro

Ninguno suelte las armas, moros fuertes y africanos, pelead con grande esfuerzo contra todos los cristianos hasta ganarles sus tierras, por Francia vamos entrando.

\section{Cuarto moro}

Ea, pues, acometamos con todo valor y esfuerzo contra todos los cristianos, hasta verlos todos muertos.

(Dan las espadas y dice el Conde)

Conde

Soldados de gran valor, ninguno vuelva la cara hasta verlos todos muertos y acabada la batalla.

Segundo derecbo

Con grande valor y modo está la gente ordenada.

A ellos, con grande brío, acábese esta canalla.

Tercero derecho

Ninguno pierda las fuerzas, 
hasta morir o vencer.

Acabemos ya con ellos, sin que se vuelvan a ver.

(Dan unos golpes contra el Conde los dos moros primeros y caen los moros en tierra. $Y$ dice el Rey moro)

¡Oh! valor de los cristianos. ¡Oh! fuerzas tan extremadas. ¡Oh! valiente Palatino, que fuerte eres en las armas. Aunque soy yo tan valiente, no he ganado la batalla.

Toda la gente está muerta, tendida por esta playa.

Segundo moro

Señor, ya no puedo más, el alma se me desmaya.

Ellos son todos muy fuertes, ninguno puede hacer nada. Mahoma estará dormido, que ojalá no recordara.

\section{Tercer moro}

Yo digo que nos marchamos, que no va buena esta Danza, porque los más ya son muertos y el diablo llevó sus almas.

Mahoma creo que es falso, Dios le dé buenas tercianas.

\section{Cuarto moro}

Yo soy de ese parecer, que ya por mi no doy blanca, porque estoy tan mal herido que pienso perder el alma.

(Pónense los moros en pie y dice el Conde)

\section{Conde}

¡Oh! fortuna que contraria.

Día mi más perseguido, que ya no puedo tenerme, creo que estoy mal herido. La batalla se ha ganado, más pienso que estoy perdido. ¡Oh! pobre de la mi esposa, si de aquesto tiene aviso. Sin duda se queda muerta, sin el menor sentido.

Dios quiera darme paciencia y que halle algún alivio.

\section{Segundo derecho}

No os aflijais, señor, ni padezca pena tanta. Retiraros a esta Venta a refrigerar el alma. Que aunque estais tan mal herido, no fueron las cuchilladas de muerte y, así, esperad de ver a tu esposa amada. Descansad ahora un poco, desde hoy para mañana, que yo asistiré con todo y lo demás que haga falta.

(Danzan y dice Golo)

Golo

Criado mío tan fiel, parte con vigilancia 
a los Campos de Turena, sin dilación ni tardanza, $y$ al gran Conde Palatino

le entregareis esta carta y le dirás por lo cierto que su esposa está preñada, de un indigno criado, de quien está enamorada. Dile que la tengo presa, en la torre retirada, para ocultar su traición y que no se sepa nada. Que yo estoy con grande pena por esta tan gran desgracia.

No dejes de informar bien, que en esto va la ganancia.

\section{Tercero derecho}

Partiré con gran cuidado

a cumplir lo que me mandas.

$Y$ aunque se halle en la guerra, le entregaré yo las cartas.

Dios vaya en mi compañía y me de fortuna y gracia.

\section{Golo}

Ve con Dios y, de la guerra, me darás noticia clara.

(Tercero derecho marcha con la embajada al segundo $y$ dice)

\section{Tercero derecbo}

Dios os guarde, buen cristiano, guardia de aqueste castillo, os pido que me digais del gran Conde Palatino, pues espero me otorgueis este favor que os pido.

\section{Segundo derecho}

Ese Conde, buen cristiano, a quien llamais Palatino, de la batalla pasada ha quedado muy herido. Pues aquí está retirado, seguidme y venid conmigo. Señor, aquí está un hombre de mucho valor y brío, me ha preguntado por vos y aquí lo traigo conmigo.

Conde, que es primero derecho

Licencia teneis de entrar.

\section{Tercero derecho}

A vuestras plantas, señor, teneis aqueste criado, a ver si me dais licencia para decir lo que traigo.

\section{Conde}

Decid, muy en hora buena, embajador, noble e hidalgo, si son cartas de mi esposa, ya las estaba esperando. Pues el no haberme escrito me tenía con gran cuidado.

\section{Tercer derecho}

De Brabante soy, señor, de vuestro mismo Palacio, de parte del mayordomo, que Golo pienso nombrarle, 
ellas son de gran dolor, pues por ellas perdeis algo.

\section{Conde}

Alguna desgracia hay, que yo hasta ahora ignoro, que es cierto que dicen bien, vengais mal, si vienes solo.

No quiero ahora leerlas, refiéremelo tú todo.

\section{Tercero derecho}

Lo que traigo, gran señor, luego quiero declararlo: vuestra esposa ha sido infiel, según Golo lo ha notado. De ello tiene gran pena y, por más disimularlo, la prendió en la torre alta donde ha parido un niño, que según dicen es hijo del más indigno criado.

A todos nos pesa mucho, no pudiendo remediarlo. Esto Golo me lo ha dicho, y esto, señor, es el caso.

\section{Conde}

¡Oh! que desgraciado hombre, que nuevas has escuchado. ¿Cómo muerte no has venido y el aliento me has quitado? ¡Oh! tan perversa mujer, cómo así has ultrajado la honra que he adquirido con tan penosos trabajos. Dónde están vuestras virtudes $y$ vuestros recreos santos. Cómo así me has ofendido, cómo tan mal me has pagado, cómo mi honra has perdido, sin vergüenza y sin reparo. ¡Oh! suerte tan sin ventura, tan digna de pena y llanto. Tu me olvidaste, traidora, pero yo te daré el pago. Yo te quitaré la vida, y haré de tu fruto un destrago. ¿Es posible, esposa mía, que tan ciega hayas andando, que sin mirar por mi honor tal traición hayas obrado? Qué laberinto es aqueste, en qué confusión me hallo. Pero decidme, mi amigo, ¿qué tiempo ha que fue el parto?

\section{Tercero derecho}

Señor, será cosa de un mes, ya diez que vos heis marchado.

Así Golo me lo ha dicho y así yo doy el recado.

\section{Conde}

¡Oh! fingida honestidad. ¡Oh! que tan poco recato. ¡Oh! que castigo merece un corazón tan ingrato. Vuélvete y dirás a Golo que sin el menor reparo a los dos cómplices mate, que así yo lo he mandado. Que yo no los vea vivos cuando vaya a mi Palacio.

Tercero derecbo, embajador

Voy con aquesta respuesta 
a dársela de contado.

Adiós, Conde Palatino,

El te alivie ese trabajo.

(Vuelve con la respuesta a Golo y dice)

Ya vengo, señor, rendido por la posta caminando. Hice lo que me mandaste y por respuesta te traigo que castigues los delitos, antes que vuelva a Palacio.

Que no los quiere ver vivos, puesto que han sido tan malos.

$\mathrm{El}$, que queda muy mal herido, en una batalla o poblado, más luego espera venir, al punto que se halle sano.

Golo

Ea, pues, amigos míos, nobles y fieles criados, id luego y a Genoveva con su hijo, dos y ambos, llevad al vecino bosque, con gran secreto y callando quitadle luego las vidas, y en el rio habeis de echarlos. Y cuidado si lo haceis, sin faltar en ello algo.

\section{Tercero derecho}

Pues no podemos rehusar el hacer vuestro mandado. $\mathrm{Si}$ es preciso obedeceros, vamos luego a ejecutarlo.

\section{Segundo derecho}

Vamos, pues que no hay remedio, a cogerlos de contado

\section{Tercero derecho}

Aquí, venimos, señora, de parte de nuestro amo, a ejecutar una orden, conforme lo ha mandado.

Dicen que habeis sido infiel, $y$ por eso ha decretado que se os quite la vida $\mathrm{y}$ al niño ${ }^{1}$ que al mundo has dado. $Y$ es preciso obedecer, sírvete de perdonarnos. $\mathrm{Y}$ así venid con nosotros al vecino bosque, entrambos.

\section{Segundo derecho}

Vámonos, sin detenernos, porque el tiempo va pasando.

\section{Dama}

Qué es aquesto, Jesús mío, qué es esto que estoy palpando, que antes por ser recatada me castigan demasiado. Adiós, esposo querido, ¿quién te sacará el engaño? A morir voy con tu hijo por un testimonio falso. A morir voy por tu honor, el que siempre te he guardado. No me pesa de mi muerte, porque tú lo has ordenado.

\footnotetext{
1 En el manuscrito: "Y al mundo que al mundo has dado".
} 
Pésame de nuestro hijo, que padre no os ha llamado.

Adiós casa, adiós castillo, adiós jardín y Palacio donde yo me recreaba con mi esposo tan amado. Adiós lucidos torreones, adiós chapiteles bajos, todos sereis mis testigos y desareis este engaño, asegurando a mi esposo que otro consuelo no hallo, que por guardarle yo $\mathrm{fe}$ voy a morir sin reparo. ¡Oh! Padre mío querido, si supieras mi trabajo, como temblaría la tierra de verte en león airado. Más ya que no hallo consuelo, quiero llamar mis hermanos: ¿dónde estais, Enrique Antonio, el valeroso nombrado? ¿Quién ahora te avisará? Cómo montado a caballo hicieras temblar la tierra, con una espada en la mano. Y tú también, Franco, el menor, que eres Rey apellidado, ¿quién te llevará la noticia de este tan fúnebre caso? Más ya esto nada sirve, Dios se digne remediarlo. Y a vos, mis fieles criados, os pido con grande llanto, que me dejeis, por un poco, hacer el niño cristiano y decir cierta oración a la Virgen del Rosario. ¡Oh! hijo de mis entrañas, toma el pecho enamorado y despídete con esto, apretado entre mis brazos, hasta que permita Dios que en el cielo nos veamos. Pues ya que pierdes la vida, en manos de dos criados, porque no pierdas el alma en el nombre de Dios Padre, Hijo y Espíritu Santo yo te bautizo, hijo mío, $y$ por cristiano te marco. $Y$ ahora, por despedida, dame, querido, un abrazo (abrázale).

Y a vos, Reina soberana, Madre de Dios soberano, os suplico humildemente que nos recibas a entrambos.

\section{Tercero derecho}

Este es el lugar, señora, que mi señor destinó, porque quitaros la vida, pésame la muerte atroz, que ...primero el niño ...ya a ver a Dios.

\section{Dama (Detenle el brazo y dice)}

Deten el brazo, atrevido, no tengas tanto rigor, mira que de mis entrañas aqueste fruto salió. Aunque es niño muy chico, es tu amo y tu señor, pues es hijo de mi esposo, aunque no quiera el traidor y atrevido mayordomo, sin conciencia ni temor, déjame darle un abrazo al hijo del corazón. 


\section{Tercero derecho}

Yo digo que los dejemos, pues me duele el corazón de verlos morir tan mal por una falsa traición; pues la condesa es muy santa, puede ser tenga razón.

\section{Segundo derecho}

También vos teneis razón y así por Dios los dejemos que entren por esos montes, porque nosotros diremos que los echamos en el río, y así los ocultaremos.

Marchad luego, id con Dios, ya nosotros nos volvemos.

\section{Dama}

Nunca Dios deja a los suyos, El quiera daros el premio.

(Marchan los dos y la dejan detrás de los de la mano izquierda, y dice)

Tercero derecho

Ya se cumplió tu mandado, ya se ejecutó tu orden, allí quedan en el río echados como salmones. entrambos los hemos muerto, mira como te compones.

Golo

Cuidado y cuenta con... que el Conde aún no ha venido $\mathrm{y}$ tengo ya por noticias que está ya puesto en camino. Yo sólo voy a esperarlo, y también a divertirlo, pues creo vendrá con pena del gran dolor que ha tenido.

(Abora el Conde sube arriba $y$ Golo baja abajo y se juntan en el medio)

Golo

$[\ldots]^{2}$

que creo traereis pesar por la mujer que heis [sic] perdido. Ya se ejecutó la orden, porque bien lo ha merecido, $y$ así perded el dolor y procurad divertiros, en paseos, juegos y cazas, y con los demás amigos, pues a mi me pesa mucho que tal haya sucedido.

\section{Conde}

Más decidme ahora, os digo, ¿mi esposa es ya muerta?

Golo

La ejecución ya se hizo ¿pues no merecía ella más por tan grande desatino?

\section{Conde}

¡Oh! desdichado de mí,

2 Los cuatro primeros versos son, en parte, ilegibles. 
conde triste y aborrecido, que me pesa de su muerte y de mi gran desvarío, pues no puedo sosegar, pienso perder el sentido. $[\ldots]^{3}$ darle tan grande castigo. ¡Oh! querida Genoveva, si acaso sería fingido, que poco me reporté, ya no sé qué es lo que digo. ¿Que no te he de ver jamás! ¿Qué es aquesto, Jesús mío?

\section{Golo}

No os aflijais, señor, ni os pese de lo dicho.

Si murió tan cruelmente, ella misma así lo quiso. Borradla de la memoria, y procurad divertiros.

(Ata los brazos y dice)

Conde

Ya no puedo vivir más, vente conmigo a la caza pues no puedo con la vida padecer tristeza tanta.

Nada puedo sosegar, todo me asombra y me pasma ¡Oh! querida Genoveva $[\ldots]^{4}$ quiero marcharme a la caza, por esos montes perdido, ver si la muerte me acaba, pues tanto tiempo ha que vivo sin comer ni dormir nada. Y ahora pienso va una cierva pasando por aquella falda, voy hasta cogerla a tiro, a seguirle las pisadas. Ya van los perros con ella, de este tiro no te escapas. Aquí se metió en las peñas, en una gruta muy alta, y allí se ve un bulto, parece ser persona humana, o es algún ...o fiera. Véamos ver si nos habla. Ella parece mujer, si la vista no me engaña, en el gruta está metida: quien mujer o fantasma, salid de entre esas peñas, si vos sois persona humana. Salid luego, pues si no, allá van estas dos balas.

(Estará con ropa vieja $y$ dice)

\section{Dama}

Los términos de la honestidad no me permiten salir

...a ver un hombre, sin primero me cubrir.

(Echale el gabán y dice)

\section{Conde}

Tómate aqueste gabán, cubríos, y aquí salid,

\footnotetext{
3 Tres versos, en parte, ilegibles.

+ Seis versos, en parte, ilegibles. Hay una anotación al final del último verso que dice: .Coge la escopeta.
} 
que quiero saber quien sois

o por qué aquí vivís;

cómo os llamáis, dónde sois

y quién vos echó aquí.

\section{Dama}

Yo soy una mujer pobre,

de Brabante natural,

nacida de nobles padres

y también de sangre real.

Casada estoy con un hombre

que es de sangre muy igual,

más por un falso traidor,

que su honor quiso robar,

me mandó quitar la vida

sin nada se asegurar.

Más ha permitido el cielo que me dejasen quedar metida en aqueste monte con mi querido Tristán ${ }^{5}$

[...]

y a mi querido Tristán, me manda Dios una cierva, que vos siguiéndola vais, que dos veces cada día la teta al niño me da.

$\mathrm{Y}$ en recompensa de eso, procura el niño juntar, un manojito de grana, y de comer se lo da. Esto es lo que respondo, a lo que vos preguntais.

\section{Conde}

Decidme, amiga, vuestro nombre.

\section{Dama}

A mi, señor, me llamaban, sin negarte la verdad, la Princesa de Brabante y, Genoveva, al nombrar.

\section{Conde (abrázala y dice)}

¡Oh! dulce y amada esposa, tu eres mi Genoveva, tu eres por quien yo muero. Estimada y dulce prenda, tu eres la que he llorado tantos años ha por muerta. ...los brazos, querida, ...los brazos, Princesa, que yo fui, esposa mía, creido con ligereza.

¿Dónde está tu amado niño? ¿Dónde está mi amada prenda? Aquel perro y traidor Golo, que me engañó con gran fuerza. Perdonadme, esposa mía, una tan grande sospecha, yo solo soy el culpable, que lo creí tan de priesa [sic].

\section{Dama}

Hijo querido y amado, que aquí me teneis sujeta, rendida a vuestro servicio, aunque pobre en esta selva. Ven, Tristán, hijo querido, ven y verás a tu padre, aunque el gran traidor no quiera.

\footnotetext{
5 Siguen cuatro versos, en parte, ilegibles.
} 
(El Conde coge al niño en brazos y la Dama por la mano y van a su sitio, $y$ antes de caminar dice)

\section{Conde}

$[\ldots]^{6}$

al Palacio, con prestanza, de aquel traidor mayordomo tomaré luego venganza.

\section{(Abora llega a un sitio $y$ dice)}

\section{Conde}

Capitán mío, va y dice, pártete con ligereza con otro de sus iguales y tráeme a mi presencia al hombre más atrevido, que es Golo, que nunca fuera, $\mathrm{y}$ bien atado con prisiones y amarrado con cadenas, que quiero tomar venganza de una acción tan grosera. Caminad luego, al instante, porque mi cólera espera, $y$ sin decirle palabra, bien asegurado venga.

\section{Segundo derecho}

Ven compañero conmigo y echémosle las cadenas

(Caminan el segundo y el tercero derechos, basta llegar a Golo, que lo prenden; le traen preso y arrodillase delante del Conde, $y$ dice)

\section{Conde}

Ven acá, perro traidor ¿cuál ha sido tu fiereza?, ¿cuál ha sido tu traición? ¿Cómo vivo aquí te llegas?, ¿qué es lo que me respondes, traidor, grosero, y que esperas?

Golo

Señor, yo bien reconozco de mi traición la fiereza, de mi alma la malicia, que os hice grande afrenta. Sin reparo ni prudencia confieso que me atreví a robar vuestro honor, y aunque pudiera escusar la fuerza de una pasión, vuestra inocencia que ha sido un delito tan atroz. He procurado, atrevido, sin conciencia ni temor, el robaros de la vida al hijo del corazón. $Y$ para merecer gracia, confieso que no hay razón.

No la deseo tampoco, más sólo os pido un favor, después que yo haya muerto de mí no os acordeis vos, ni de mis malas acciones ni del menor rigor.

Mándame quitar la vida, pues el vivir ya es peor.

\section{Dama}

Perdónalo, amado esposo,

- Seis versos, en parte, ilegibles. 
perdónalo de todas veras, porque también Dios perdona

a los que hacen ofensas.

Conde

No es digna de perdonar esta tan grande traición.

Porque si esta le perdono, otra ha de hacer peor.

Para con Dios, le perdono, pero su castigo, no.

Porque no pierdas tu alma, di el acto de contrición, que te van estas dos balas derechas al corazón.
Golo

Señor mío Jesucristo

Dios y hombre verdadero

yo soy aquel pecador

que $\tan$ ofendido os tengo

$[\ldots]^{7}$

ahora me sale bien pago.

Recibidme, Dios del cielo,

si me teneis perdonado,

quiera Dios que todos juntos

en el cielo nos veamos.

(Abora le hecha [sic] el Conde un tiro a Golo)

CONCEPCIÓN CASADO LOBATO

Instituto de Filología

CSIC, Madrid

' Cinco versos, en parte, ilegibles. 